\title{
Explorative Configuration of Supplier Cooperation as an E-Marketplace Service
}

\author{
Heiko Thimm and Kathrin Thimm \\ University of Applied Sciences Kiel, Institute for Business Information Systems, \\ Sokratesplatz 2, 24149 Kiel, Germany \\ heiko.\{thimm, kathrin, thimm\}@.th-kiel.de
}

\begin{abstract}
Supplier E-Marketplaces prevalently offer composite products that require complex production processes where multiple suppliers cooperate with each other. Since collaborating suppliers often hold overlapping production competencies multiple process alternatives may exist where production steps are allocated to suppliers in different ways. This process variability may be exploited for a supplier configuration engine where customers, similar to a product configuration engine, may control the handlers of the production process according to own needs and preferences. We present and discuss an initial set of configuration criteria for such an engine and a first pilot architecture for a corresponding E-Marketplace service.
\end{abstract}

Keywords: E-Commerce, Electronic marketplace, Internet business collaboration, Inter-organizational enterprise systems

\section{INTRODUCTION}

For some branches where products are sold to consumers over the Internet via supplier portals, buyers expect a product configuration engine. Examples for these branches include the computer and furniture business. However, product configuration engines have also become popular for B2B E-Marketplaces. This holds especially true for business with semi-finished products, i.e. composite products which can be found in the manufacturing industry, for example. Such composite products are only rarely manufactured by a single company alone. Instead, often they are produced by multiple companies jointly together. It appears that such cooperation initiatives are in many cases based on specific forms of alliances such as Production Networks and Virtual Companies [1, 2]. From concrete examples in the manufacturing industry it can be observed that such alliances are often geared at a built-to-order business model for a predefined product offering. That is, the composite products are manufactured jointly by the collaborating companies according to customer orders.

Normally, complementary production competencies exist among the companies of such supplier alliances. Otherwise, there would hardly be any reason for a joint product offering. But, in addition to such complementary competencies it appears that 
often the competencies overlap partially, too. This implies that a single production step required for a composite product may be allocated not only to a single but often to multiple alternative suppliers. The more companies with similar production competencies are part of the organization, the more allocation alternatives for each production step exist. Consequently, for each offered composite product considered can be multiple production process variants with different assignments of companies to production steps.

In principle, two different approaches exist for dealing with this variability of the production processes. Either, the variability is managed inside the supplier organization or it is exposed to the buyers. Research targeted on the first approach where the variability is handled by tendering or by a moderator of the supplier organization, e.g., can be found in $[1,3,6]$. In the research presented in this article, we investigate the second option where the variability of the production processes is exposed to the potential buyers through a novel E-Marketplace service. Our approach is based on the hypothesis that B2B E-Marketplace customers often got a strong interest in giving guidelines for the allocation of suppliers to production steps needed for a composite product. For example, they want that only companies of their own choice are being considered while others, with whom they made negative experience, are being excluded from the manufacturing process. Furthermore, customers want to choose themselves criteria to evaluate different allocation options and to identify through these criteria the best alternative among all potential options. For example, they want to decide themselves whether the manufacturing process for the offered composite product should be fulfilled by the quality champions or the cost champions of the supplier organization.

The overall framework of our research is the eBusCo.net Project, a German-Danish international research project on "Electronic Business in Company Networks" funded by the European Union within the Interreg IIIa program.

The remainder of this article is organized as follows. In Section two, we discuss possible criteria that allow buyers to control the supplier configuration. Section three presents our architectural approach towards a corresponding marketplace service and describes central design considerations, too. Concluding remarks and future work are contained in Section four.

\section{CRITERIA FOR SUPPLIER CONFIGURATION}

As discussed in the previous section, when multiple suppliers cooperate, composite products may often be produced in multiple alternatives ways. We refer to these alternatives as supplier configurations that differ from each other with respect to the combination of suppliers chosen for the production steps. It is our goal to give customers a possibility to explore different supplier configuration options in terms of meaningful evaluation criteria and to discover through that the ultimate choice that fits best to individual needs and preferences.

In our approach, we differentiate between two types of criteria for supplier configuration. Explicit Configuration Constraints refer to hard constraints that must be satisfied. For example, such hard constraints address the situation where a buyer 
wants to exclude a specific supplier due to earlier negative business experience gained with this supplier. Table 1 presents examples for Explicit Configuration Constraints.

Table 1. Initial Set of Explicit Configuration Constraints

\begin{tabular}{|l|l|}
\hline Constraint & \multicolumn{1}{|c|}{ Explanation } \\
\hline INCLUDE & Specifies a supplier that has to be included in the supplier configuration. \\
\hline EXCLUDE & Specifies a supplier that must not be included in the supplier configuration. \\
\hline MUTUAL & $\begin{array}{l}\text { Specifies a pair of suppliers that must not be included in the supplier } \\
\text { EXCLUDE }\end{array}$ \\
\hline
\end{tabular}

Configuration Goal Criteria refer to (soft) criteria that may be used to evaluate a single set of collaborating suppliers, that is a single supplier configuration alternative. As the term "goal criteria" indicates, through these criteria the best choice among a number of potential configuration alternatives may be found. Note that we expect that in practice buyers want to consider multiple goal criteria at the same time. It is part of our future research to gain more insights into the issue of conflicting criteria. We present an initial set of such criteria in table 2 .

Table 2. Initial Set of Configuration Goal Criteria

\begin{tabular}{|l|l|}
\hline \multicolumn{1}{|c|}{ Criterion } & \multicolumn{1}{|c|}{ Explanation } \\
\hline $\begin{array}{l}\text { Production } \\
\text { Experience }\end{array}$ & $\begin{array}{l}\text { This criterion gives preference to suppliers with a high degree of } \\
\text { experience in the needed manufacturing steps. }\end{array}$ \\
\hline $\begin{array}{l}\text { Production } \\
\text { Quality }\end{array}$ & $\begin{array}{l}\text { Preference is given to companies with high-quality production processes } \\
\text { which may be evaluated through dedicated methods such as Six Sigma. }\end{array}$ \\
\hline Price & $\begin{array}{l}\text { Preference is given to companies that will ask relatively low production } \\
\text { prices so that a low total price for the composite product is achieved. }\end{array}$ \\
\hline $\begin{array}{l}\text { Geographical } \\
\text { Distance }\end{array}$ & $\begin{array}{l}\text { Preference is given to a small geographical distance between the suppliers } \\
\text { such that required are only minimal efforts for the material transportation. }\end{array}$ \\
\hline $\begin{array}{l}\text { Financial } \\
\text { Strength }\end{array}$ & $\begin{array}{l}\text { This criterion implies that preference is given to suppliers with a strong } \\
\text { financial power, for example, for the purpose of investment protection. }\end{array}$ \\
\hline
\end{tabular}

\section{CONSIDERATIONS FOR A SUPPLIER CONFIGURATION SERVICE}

It is the core idea of this paper that there is a demand for E-Marketplaces which may cope with the above described supplier configuration task through a corresponding supplier configuration engine. Through such an engine buyers may explore con-figuration alternatives according to own needs and preferences. This calls for an adaptable configuration engine approach that may support criteria as discussed in section 2. We are currently implementing such an engine as an isolated, standalone system in order to obtain first experimental results from the practice. We give a brief overview of this first pilot in the remainder of this section. 
Figure 1 presents in the left part the principle approach of our pilot system and in the right part the layout of the Graphical User Interface (GUI) for buyers. The buyer GUI in the upper window frame allows a buyer to pick a specific composite product from a given list and to view the corresponding component products. In the frame directly below the buyer can select configuration criteria as presented in section 2 according to own preferences and submit the specified configuration request to the engine through the "configure" button. The configuration result is presented to the buyer in the lower window frame. Displayed are the three top most scoring configuration alternatives. Each alternative is presented as list of corresponding component products and each product is augmented with a supplier chosen by the configuration engine. Textual explanations of the configuration result are presented in the sub-frame at the right side.
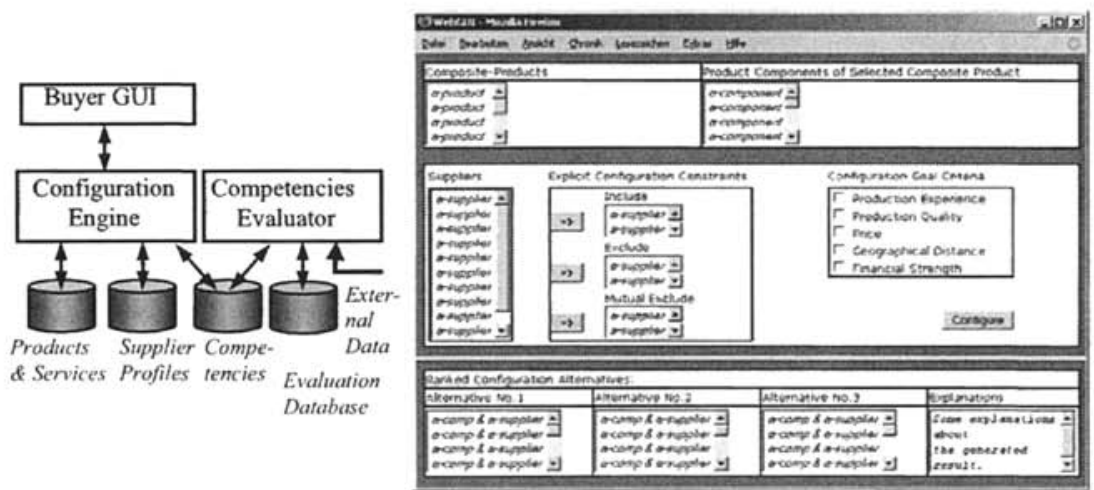

Figure 1. Pilot System Architecture and Buyer GUI of proposed E-Marketplace Service

The data processed by our pilot are organized into four repositories. The Products and Services Repository contains detailed information about the composite products offered. This includes especially the Bills of Materials (i.e. all parts of the composite product) and the manufacturing process definitions that specify the corresponding production steps. For the implementation of this repository we will leverage preexisting research results on effective and standards-based representation of products and services such as described in [4]. In the Supplier Profiles Repository, general information about the suppliers are maintained including number of employees, size of production facilities, areas of specialization, compliance to quality standards, and financial information. The competencies of each supplier in terms of the product portfolio are maintained in the Competencies Repository. Similar to the "Competencies Maps" described in [5], our competency descriptions state the price limit and quality level that suppliers guarantee for component products. In the Evaluation Data Base, data about orders completed by the supplier organization are stored. These data are loaded from the corresponding external business execution environments. This loading and subsequent storing of the data in the Evaluation Database is frequently performed by the Competencies Evaluator. From the Evaluation Database new 
competency data are repeatedly derived and then inserted into the Competencies Repository.

The Configuration Engine takes the user input and displays the configuration result that is computed through a corresponding configuration scheme. Our scheme is based on a multi-criteria scoring approach. In the first step, the potential configuration alternatives are computed under consideration of the given Explicit Configuration Constraints. In the second step, the alternatives are evaluated with respect to the buyer's individual Configuration Goal Criteria. A scoring approach is used to map the evaluation results that relate to criteria specific scales into corresponding numeric scores. All of these numeric scores are computed together to a total score for each alternative. Based on the total scores a ranking of the alternatives is obtained and returned to the user as configuration result.

\section{CONCLUSIONS AND FUTURE WORK}

We presented an approach for a novel service that enables buyers to explore collaboration alternatives for a set of companies that jointly produce composite products. Buyers may use this service in an explorative manner to discover the supplier configuration alternative that fits best to individual needs and preferences. Early discussions with companies of the manufacturing industry have shown that our service is indeed considered as an enrichment of today's supplier E-Marketplaces. We expect more insights through further simulation and empirical studies with our pilot system. Also, a forthcoming survey of 1,000 manufacturing companies will give us feedback about our initial set of configuration criteria. Our future work will also include technical revisions of the prototype. This will include concepts for the integration of our service in existing E-Marketplace environments.

\section{REFERENCES}

1. A.A. Pereira and E.R. Klen, Human Supervised Virtual Organization Management, in IFIP TC5/WG5.5 Working Conf. on Virtual Enterprises 2005 (Springer: 2005), pp.229238.

2. D. Vanderhaeghen and P.P. Loos, Process Modelling Framework for Collaboration Networks, in Workshop on Process Integ. of Collab. Enterprises (Manchester, 2006).

3. T. Hess, Planning and Control of Virtual Corporations in the Service Industry - The Prototype VICOPLAN, HICSS-35 (2002), pp.24-33.

4. M. Hepp, J. Leukel, and V. Schmitz, A Quantitative Analysis of eCl@ss, UNSPSC, eOTD, and RNTD: Content, Coverage, and Maintenance, IEEE ICEBE (2005), pp.572581.

5. A. Hammami, P. Burlat, and X. Boucher, Distributed Enterprises Configuration: Orders Allocation within Networks of Firms, in Proc. of IFIP TC5/WG5.5 Conf. on Collaborative Business Ecosystems and Virtual Enterprises '02 (Kluwer, 2002), pp.219-226.

6. H. Thimm, Computing Network Actor Sets for Efficient Request Management in Company Networks, eChallenges Conference (The Hague, Neth, 2007). 